\title{
A formação de um mestre: saberes em circulação na cultura popular*
}

\author{
Isabel Cristina Martins Guillen**
}

\section{Entrevistando o Sr. Zezinho}

Alto de Santa Izabel, zona norte da cidade do Recife. Entre as décadas de 1930 e 1980, o bairro foi sede do maracatu Cambinda Estrela, primeiro como maracatu de orquestra, para nos anos sessenta virar o baque e se tornar maracatu-nação. Lá ainda vivem antigos brincantes, a exemplo de D. Leinha, Aprígio e Givanildo, que em momentos diferentes desfilaram no maracatu. O Sr. José Amaro de Souza Filho foi caboclo de lança do maracatu, quando ainda era "garotote", e ainda hoje reside no bairro, tendo se tornado um afamado pai de santo. No entanto, é mais conhecido como "seu" Zezinho, ou como ele gosta de se referir, Zezinho de Zé Vieira, que foi seu mestre de coco, com quem aprendeu a arte da rima e do desafio.

Entrevistamos o Sr. Zezinho quando nos propusemos a fazer uma história do Maracatu Nação Cambinda Estrela, que em 2005 completou 70 anos. No carnaval desse ano o Cambinda Estrela (que atualmente encontra-se sediado no bairro de Chão de Estrelas, também zona norte da cidade do Recife) promoveu um desfile pelas ruas do Alto de Santa Isabel, e antigos brincantes puderam rememorar os tempos em que o maracatu

Trabalho apresentado no V Encontro de História Oral do Nordeste. São Luis, 05 a 09 de setembro de 2005.

** Professora do Departamento de História da Universidade Federal de Pernambuco. 
lá se encontrava sediado. O desfile nos propiciou perceber as vinculações afetivas e culturais desses antigos brincantes com o maracatu e o bairro; expressões como "o maracatu nunca deveria ter saído daqui" foram ouvidas mais de uma vez, indiciando que ali se encontrava uma boa história para se pensar.

As entrevistas realizadas ${ }^{1}$ apontam complexas questões sobre as redes culturais e de sociabilidade que suportam o fazer da cultura popular, indicando a construção de uma territorialidade cultural que extravasa o âmbito urbano, adentrando a zona da mata ao norte de Pernambuco. Essa territorialidade cultural, por outro lado, se construiu num andejar constante pelos bairros periféricos da cidade, nas passadas cotidianas pelas feiras, terreiros de Xangô, botequins e muitos outros espaços. Como andava essa gente! Sem dinheiro para o transporte coletivo, subiam e desciam os morros para sambar coco e maracatu, namorar, ir ao trabalho, ou às festas de xangô. "Os jogos dos passos moldam espaços. Tecem os lugares. Sob esse ponto de vista, as motricidades dos pedestres formam um desses 'sistemas reais cuja existência faz efetivamente a cidade', mas 'não tem nenhum receptáculo físico'. Elas não se localizam, mas são elas que espacializam" (Certeau, 1998, p. 176). Um outro Recife emerge nessas entrevistas.

Ao se fazer uma entrevista, não se pode deixar de ter certa visão crítica do "informante" como "fonte". Acredito que é fundamental que se aprenda a ouvir, que se crie para o informante a oportunidade de criar sua narrativa, criar os caminhos a serem percorridos na e pela memória. Isto não significa que devemos ir para a entrevista "desarmados", ou sem um roteiro prévio de questões. Mas é fundamental que esse mesmo roteiro não tenha um papel predominante na entrevista a ponto de cercear um certo "fluxo" da memória. É fundamental igualmente que o entrevistador possa reconhecer o poder que exerce naquele momento, e os modos como esse mesmo poder pode conduzir ou encaminhar a entrevista, muitas vezes sem que o pesquisador dele se aperceba (Harrits e Sharnberg, 2000).

1 As entrevistas foram realizadas por mim e por Ivaldo Marciano de França Lima, mestre do maracatunação Cambinda Estrela e mestrando em história na UFPE. 
Com o Sr. Zezinho esta questão foi expressamente colocada, logo no início da entrevista, quando disse: "Olhe, falar pra vocês, não é mole não, principalmente pra você, que eu não pensei que você é o que me disseram que você é. Eu não sabia não, você é tão simples." "Seu" Zezinho se referia à minha condição de professora da Universidade, que parecia se chocar com a de também brincante do Maracatu Nação Cambinda Estrela. Eu tinha chegado no Alto Santa Izabel acompanhando o maracatu nas comemorações de seus setenta anos, e demonstrei a intenção de entrevistar os antigos brincantes, como o Sr. Zezinho e outros. Quando o Sr. Zezinho colocou minha "autoridade" em pauta e sua "dificuldade" para falar foi necessário firmar um pacto de que as autoridades eram mútuas, e que o conhecimento não era do "domínio" de ninguém. O Sr. Zezinho em nenhum momento deixou de ser cioso de seu conhecimento, afirmando e reiterando que não encontraríamos informantes que pudessem nos dar as informações que queríamos tal qual ele as possuía. Em alguns momentos da entrevista, ele chegou mesmo a inverter os papéis, dizendo: "Agora você me pergunte: e a roupa do caboclo, como é a roupa do caboclo?" Passava em seguida a responder sua questão.

Numa primeira avaliação, o Sr. Zezinho poderia ser considerado um homem muito vaidoso. Mas me pareceu algo mais, ele é consciente do poder que tem como pai de santo, terreno no qual o saber é plenamente poder, de curar, de provocar benefícios, encontrar amores, ou desunir casais... Também se mostrou cioso do saber que detém como mestre coquista, do saber que detém acerca da cultura popular, do seu território, do conhecimento da cidade, das ruas e bairros, das cidades do interior e do domínio de sua arte: o versejar, sambar o coco. Ao final da entrevista, após ter demonstrado uma excelente capacidade de improvisar nas rimas e versos, afirmei que ele era muito bom, ao que me respondeu:

Não, não sou bom não, mais ou menos. Eu acho que a senhora até hoje não fez uma entrevista como essa que ta fazendo aqui não. Eu tenho certeza. Eu digo o exemplo, porque eu gosto muito de dizer as coisas, o que sai de mim às pessoas. Eu tenho segurança no que to dizendo. Que pra falar com a senhora, precisa ter segurança e saber o que ta falando. Principalmente que eu nem sabia quem era você. Você é muito preparada. Preparadíssima. Eu pra você não sei nem pegar nesta caneta. Agora, mas no improviso, 
pode trazer se você tiver um bom lá que cante, vocês traga. E quando quiser fazer uma brincadeira de coco, de São João, pode vim. Se tiver um duro lá que diga, eu sou cantador, pode chamar ele e pode vim. E me faça o convite.

Enfim, terrenos delimitados. Eu sou professora, preparadíssima. Mas em se tratando de coco, ele é o mestre. ${ }^{2}$

\section{O Alto de Santa Izabel e a cultura popular}

Final dos anos vinte do século passado, início dos anos trinta: a cidade do Recife passa por intensas transformações urbanas. Apesar da cantilena que apregoa a crise econômica no mercado do açúcar, a cidade cresce, incha no dizer de alguns, exigindo reformas e infra-estrutura que suporte tal crescimento. De um lado, sobressai a ânsia pela modernidade que atinge a vida cotidiana dos mais abastados, daqueles que moram nos bairros centrais e que freqüentam teatros, cinemas e cafés no centro da cidade. De outro lado, as discussões e campanhas contra os mocambos dão uma visibilidade para os modos de morar dos mais pobres, revelando a miséria que circunda a cidade, que penetra em becos e ruelas. A zona norte da cidade, principalmente seus morros, que se tornarão conhecidos como "Altos", estava sendo ocupada freneticamente, uma vez que o centro da cidade não comportava mais novos moradores. Alto Santa Izabel, Alto José do Pinho, Alto do Mandu, dentre outros, vão sendo ocupados por essa gama de trabalhadores pobres expulsos do centro, principalmente do bairro de São José, ao mesmo tempo em que a cidade assiste um intenso movimento migratório de trabalhadores rurais, também expulsos das usinas e engenhos (Rezende, 1997; Lira, 1996; Levine, 1980).

Nesse contexto, o Alto Santa Izabel, situado próximo ao mercado de Casa Amarela, coração da zona norte do Recife, rapidamente foi povoado, principalmente por ter uma localização privilegiada. Ruas sem calçamento, casas de taipa e capim, raros postes de madeira a iluminar o bairro durante a noite. Na Rua Carolina o Sr. Manuel Martins, trabalhador

2 Sobre os mestres de maracatu e coco, ver: Nascimento, 2000 
rural originário de Nazaré da Mata, construiu uma casa fixando residência para sua família. Aos poucos, outros parentes se mudaram para as redondezas, primos, tios, irmãos, constituindo uma rede de solidariedade que fazia a vida cotidiana suportável, propiciando em meio aos afazeres que proviam à vida material do grupo, uma série de práticas culturais que lhes permitiam re-significar suas vidas no novo local (Certeau, 2003). Assim, nessa mesma casa funcionava a sede do Maracatu Cambinda Estrela, fundado por Manuel Martins, que D. Leinha, sua filha, faz questão de frisar com recorrência que tinha verdadeiro amor aos brinquedos (entrevista concedida em 10/02/2005). Além do maracatu, seu Manuel Martins também fazia cavalo marinho e principalmente o coco na época das festas juninas. Mais do que simplesmente brinquedos de pura diversão, essas manifestações culturais vão se constituir em pontos nodais dessas redes sociais, permitindo a recriação de práticas culturais típicas da zona da mata canavieira, transitando entre o mundo rural e o urbano, entre a cidade e os engenhos, criando outros sentidos e significados simbólicos, conforme podemos conferir no depoimento de D. Leinha a respeito de seu pai, o Sr. Manuel Martins.

Agora meu pai que gostava muito de brincadeira, esse negócio de diversão era com ele. A única coisa que ele não gostava era de dança. Dança ele não gostava não. Ele já teve cavalo marinho, botou cavalo marinho aí na frente... No interior é que tem né, boi, né, esse negócio. Ele tinha boi, tinha cavalo, eu era garota ainda... e gostava de São João, esse negócio de coco, de roda. Começava o coco na véspera de Santo Antônio, só ia terminar no sábado de Santana. Era coco toda semana, sábado pro domingo o coco aqui virava, toda semana, a noite todinha. E naquela época não tinha só o pandeiro tocando. Naquela época era o bombo mesmo, aquele bombo que é do maracatu... a noite todinha o bombo tocando. Quando dava quatro, quatro e meia, ia tudinho cantando, ia pra Bebinho tomar banho, no rio de Bebinho. Meu pai toda vida gostou de brincadeira, essas coisas.

O Sr. Manuel Martins ficou alguns poucos anos à frente do Cambinda Estrela, logo assumindo a direção do maracatu o Sr. Tercílio, que se tornaria uma dos mais afamados mestres de maracatu de toda a cidade 
do Recife. "Como ele, não tinha outro não", afirma o Sr. Zezinho. A Rua Carolina, onde era a sede do maracatu, fica próxima também do local denominado Outeiro de Santa Izabel onde, de acordo com a memória de diversos moradores, funcionavam vários bordéis, e muitos se referem à região como violenta e perigosa. Em ruas transversais e paralelas funcionam muitos outros brinquedos, além de outros maracatus: Maracatu Cambinda Nova, Maracatu Leão das Flores, Maracatu Pavão Dourado, Maracatu Som do Oriente. Todos estes maracatus são de orquestra, assim como o Cambinda Estrela, e começavam a chamar a atenção dos intelectuais da cidade, principalmente os caboclos de lança e os tuchaus, figuras que até então não circulavam com freqüência pelas ruas centrais da cidade no período do carnaval (Guillen, 2003).

Existem dois tipos de maracatus na cidade do Recife. Os maracatusnação, que são constituídos por um cortejo real, em que se sobressaem rei e rainha acompanhados de um conjunto musical de percussão. Estes são os grandes maracatus originários das coroações de reis do Congo, descritos por Pereira da Costa e Guerra Peixe, por exemplo. Os grupos que mais se destacaram foram o Elefante, o Leão Coroado, o Dois de Ouro, dentre outros. Nos anos de 1930 e 1940 algumas figuras de maracatu começam a chamar atenção de observadores mais atentos às manifestações da cultura popular, como o pintor Lula Cardoso Aires, que fotografou "os indecifráveis tuchaus" e os famosos caboclos dos maracatus que hoje denominamos de orquestra ou "rural".

A grande diferença com o maracatu-nação está na formação do conjunto musical, composto de uma orquestra com instrumentos de sopro e de um terno. Esses maracatus de orquestra ganham visibilidade pela cidade nesse período, mas foram confundidos com os seus congêneres, e muita discussão houve na definição dessas manifestações, consideradas descaracterizações dos autênticos maracatus, até o momento em que o maestro Guerra Peixe estabeleceu as diferenças entre ambos, principalmente do ponto de vista musical. Tais maracatus provavelmente surgiram na cidade em decorrência dessa migração da zona da mata canavieira para a periferia do Recife, conforme nos referimos acima (Peixe, 1981; Os indecifráveis tuchaus. Contraponto, Recife, março de 1947; Real, 1990; Lima, 2004).

Além dos maracatus, no Alto Santa Izabel funcionavam muitos outros brinquedos, tais como cavalos marinhos, bois, presépios e pastoris, 
além de quadrilhas e festas de coco, sempre a depender do ciclo das festas populares (Natal e festas juninas, por exemplo) Acrescente-se a esse rol uns tantos terreiros de religiões afro-descendentes, como os Xangôs e Juremas. Concomitantemente ao crescimento da zona norte do Recife, assistiu-se nos anos de 1920 a uma intensa repressão desses brinquedos populares sob vários pretextos, entre os quais se destacava o desejo de instituir disciplinas que extirpariam hábitos considerados incivilizados, propícios à violência e à criminalidade (Couceiro, 2003). Esses divertimentos populares, no entanto, podem ser entendidos como pontos nodais nas redes de solidariedade que se constituíam entre parentes e vizinhos, visíveis principalmente na organização, próxima ao Natal, dos chamados presépios de crianças. O discurso da elite a respeito dos brinquedos da cultura popular, além de o considerarem práticas não civilizadas, aventavam todo o tempo que as mesmas eram propícias a práticas violentas. É nesse sentido que a Secretaria de Segurança Pública exigia que os brinquedos tirassem licença para funcionar, e a polícia enviava inspetores ao local para saber se "perturbavam a ordem pública" ou "provocavam desordens", antes de autorizar o funcionamento dos mesmos. ${ }^{3}$

No entanto, nas memórias do Sr. Zezinho, a imensa variedade de brinquedos de que participou não aparecem como naturalmente propícios à violência; ao contrário, eram espaços de lazer e sociabilidade em que eventualmente ocorriam brigas. O Sr. Zezinho tem seu terreiro na mesma Rua Carolina. Apesar da fama de que os maracatus rurais eram brinquedos violentos, que os caboclos não perdiam a chance de provar seu caráter aguerrido, o Sr Zezinho lembra de poucas brigas.

Aqui no Alto de Santa Isabel, no tempo que era o Outeiro, que era gafieira. Pronto, tinha um bumba meu boi de Antonio Torres, lá perto do terminal, o Garrote Novo, que quem cantava as toada do boi era uma velha e balançava o ganzá e cantava a noite todinha. Mãe de Estevão, que era o porta-bandeira de Leão de Aldeia. [...] Agora, saía e não tinha um barulho. Todo mundo bebendo aguardente.

3 Essas autorizações encontram-se principalmente nos volumes da Secção de Teatros e Diversões Públicas da Repartição Central de Polícia - Fundo RCP do Arquivo Público Estadual. A pesquisa nesses volumes foi efetuada pelas bolsistas de iniciação científica Débora Callender e Bartyra Queiroz. 
O dono do bumba meu boi era Antonio Torres. Chegava pra aquele lado de Tercílio (do maracatu Cambinda Estrela) ali passava mais de duas horas batendo. ${ }^{4}$

O que se destaca nas memórias do Sr. Zezinho é essa quantidade de pessoas que conheceu e que participavam de diversas brincadeiras: havia músicos que tocavam em maracatus, bois e cavalos-marinhos, havia desfilantes que saiam no carnaval nos maracatus e que eram nas festas juninas organizadores de quadrilhas ou participantes de rodas de coco. O relato do Sr. Zezinho nos levanta pistas de que essa rede em que os brinquedos estão inseridos é extremamente complexa e diversificada, cada membro participando de muitas coisas, utilizando suas habilidades em diferentes situações. Há uma intensa dinâmica social que contrasta com a idéia de que esses brinquedos são tradicionais, folclóricos, tomando essas expressões como não apensas a mudanças. Ao mesmo tempo, essa rede se estende ao mundo rural, aos engenhos e cidades da zona da mata norte do Estado, Carpina, Nazaré da Mata, Vicência, dentre outras. No carnaval os maracatus de orquestra costumavam se apresentar nessas cidades do interior, demonstrando que sua vinculação com o mundo rural não havia se desfeito. Desse modo, a partir da memória de antigos moradores do Alto Santa Izabel, podemos discutir as práticas culturais e constituição de redes de sociabilidade que esses brinquedos propiciavam, permitindo a homens e mulheres não apenas suportar a vida cotidiana, mas simbolizar sua inserção no mundo. Foi em meio a esse rico e diversificado contexto que o Sr. Zezinho, ainda "garotote", se apaixonou pelo coco.

\section{O coco, o samba de maracatu e seus mestres}

O leitor que se aproximar da cultura popular de Pernambuco poderá constatar que, apesar da pluralidade de manifestações culturais, poucos estudos acadêmicos foram realizados sobre as mesmas, principalmente quando se exige o mínimo de sistematização que nos permita analisar sua diversidade. Em se tratando de coco e maracatu de orquestra os estudos

4 Entrevista com o Sr. José Amaro de Souza Filho (Zezinho de João Vieira) realizada em 24/04/2005. 
são extremamente rarefeitos e, em muitos casos, reproduzem lugares comuns acerca da cultura popular, reiterando afirmações extremamente questionáveis, "folclorizando-as", ou seja, sem se preocupar com a história dessas manifestações, não verificando as suas possíveis transformações. Imobilizadas no tempo como tradições, essas manifestações da cultura popular foram recorrentemente retiradas de suas redes sociais que lhes conferem historicidade, e fornecem um arsenal simbólico que permite aos brincantes um constante re-significar de suas práticas culturais e cotidianas.

O maracatu rural tem despertado na atualidade maior interesse, e começam a despontar algumas teses e dissertações. Mas em se tratando de coco, a sensação é a de estar desbravando um terreno inexplorado, ao menos em Pernambuco. Por que Câmara Cascudo (2001), no seu Dicionário do Folclore Brasileiro, não se refere ao coco em Pernambuco? E em Recife, teria essa manifestação cultural se firmado na zona norte da cidade a partir do processo de migração rural-urbano? Estas e muitas outras questões sobre a presença do coco na cidade do Recife ainda esperam respostas.

Importa destacar que, em sua passagem pelo Nordeste, Mário de Andrade foi tomado de paixão pelo coco, e seu projeto de escrever $\mathrm{Na}$ pancada do Ganzá estava centrado em grande parte na recolha que fizera pela Paraíba. Assim, a Missão Folclórica de 1938 tinha como um de seus objetivos centrais gravar os cocos e coquistas por quem Mário tinha se encantado (Andrade, 1984; 1976; Carlini, 1994; Ayala, 1999).

Segundo Câmara Cascudo (2001), existe uma variedade enorme de tipos de coco, e as designações que recebe estão relacionadas a diversos elementos, como os instrumentos utilizados, a forma do texto poético, o lugar em que é executado e o processo poético musical. ${ }^{5}$ A proximidade poética com os maracatus rurais, com a cantoria de viola e com o repente também nos aponta para uma enorme circularidade cultural entre essas diversas manifestações da cultura popular, demandando novas pesquisas (Ginzburg, 1987).

Não é nosso objetivo neste trabalho, infelizmente, suprir as lacunas a respeito do coco, apenas apontar a complexidade que envolve o

5 Ver também, sobre o maracatu rural e sua semelhança em termos de desafio com o coco: Amorim, 2002. 
processo de transmissão e formação de seus mestres, a partir da memória do Sr. Zezinho. No processo de transmissão do saber a memória é recurso imprescindível. Trata-se de um vasto saber que se produz e reproduz através da oralidade, e é fundamental que o cantador tenha uma memória prodigiosa para guardar vários cocos, marchas, sambas que compôs, ou que outros compuseram. O Sr. Zezinho revelou possuir essa memória prodigiosa. À medida que lembrava de sua vida, vários acontecimentos foram pontuados com um coco ou marcha de maracatu que tinha marcado aquela ocasião. Nesse sentido, a rima e a música não só servem de suporte para a memória, mas para contar uma história, revelando complexos significados que coco e maracatu adquirem para a vida dessas pessoas. Numa ocasião em que o Maracatu Cambinda Estrela encontrou pelas ruas da zona norte com seu rival, o Águia de Ouro, evitou-se com diplomacia uma briga, comum nesses encontros. O mestre do Cambinda, o Sr. Tercílio, na ocasião compôs de improviso uma marcha: Águia de Ouro vai embora em teu caminho/Tu vai subir o Outeiro, eu vou pra José do Pinho. E o Sr. Zezinho, em sua entrevista, complementa: "Tercílio cantou essa marcha, eu era garotote, eu ainda me lembro."

Ser mestre de coco é uma condição da qual o Sr. Zezinho tem muito orgulho. Ele fez questão de nos contar como se tornou um mestre, numa relação em que vários elementos se destacam: suas próprias qualidades bem como as de seu mestre, a persistência no aprendizado e, acima de tudo, a constância com que participava nessa rede de músicos e cantadores que existia na cidade do Recife, especialmente na zona norte. É importante destacar que as atividades do Sr. Zezinho como coquista nos surpreenderam, pois eram inesperadas. Em grande parte da entrevista ele conduziu sua memória para narrar cocos, suas regras de composição, para falar de outros grandes mestres que tinha conhecido, sem que o interrogássemos a respeito. Nosso interesse estava no maracatu, mas para a vida do Sr. Zezinho, o coco se sobrepunha.

No entanto, muitos desses músicos e cantadores participavam de várias manifestações, eram mestres de maracatu e cirandeiros, como Antonio Baracho, ou coquistas e maracatuzeiros, como ele próprio. As diferenças entre uma e outra são sutis e complexas, revelando que a experiência é fundamental para se alçar à condição de mestre.

O Sr. Zezinho nos conta que manifestou o desejo de aprender a tocar e cantar coco ainda menino, e pediu a Antonio Roxinho, integrante 
do Cambinda Estrela, que o ensinasse. Este teria lhe respondido que ainda era aprendiz, por isso não podia lhe ensinar.

Aí eu me encostei junto de João Vieira. Um dia eu tava aqui, aí disseram: "tem um coco no córgo da Embaúba em Nova Descoberta, logo na entrada, depois do largo Dona Regina, à direita..." Eu já cantava alguma porquera, errado, desmantelado, chama porquera quem canta desmantelado, não faz a rima certa. Aí eu cheguei, tava seu João cantando na casa de Joel Aguardenteiro, ele somente de filha tinha seis e três homens. As meninas tudo sambando, eu rapazote mais ou menos com dezesseis anos, aí tava os cantador tudo com pandeiro encostado num canto da parede e João Vieira cantando sozinho. Aí vai e sai Zé Cesário, que foi mestre de maracatu e era do Engenho Camaleão, era de Nazaré da Mata, e diz: "João, aí fora tem um cantador". Quem tava era eu! Aí seu João chegou, a casa era grande, a porta de dois gomos, aí disse: "Quem é o cantador aí?" Aí eu olhei pra um canto, olhei pra outro, o pessoal olhando tudo pra mim. Eu não tava com pandeiro, não tava com nada, cantador era os que tava dentro da sala! Aí Cesário disse, aquele moreno. Aí seu João disse: "É o senhor o cantador?" Respondi: "Eu não sou cantador não, mas eu faço meia sola". Ele disse, "Entre", pegou o pandeiro dele e me entregou, e disse: "Cante". Aí no meio da mocidade, eu fui ao pandeiro e cantei, ele escutou, escutou, escutou. Parou e disse: "Ta vendo vocês? Vocês desde hoje que tão aí e não tem coragem de vir cantar, o rapaz chegou, num tava com pandeiro, eu peguei o pandeiro e dei e ele tocou. Ele não é um cantador ainda não, mas promete ser um grande cantador." E disse, fique aí cantando que eu vou tomar um cafezinho. Aí eu digo: "Venha Cesário", que era o melhorzinho que tinha, que era mestre de maracatu e entendia o que era rima.

A partir desse momento, o Sr. Zezinho passa a seguir João Vieira, torna-se seu aprendiz. Esse processo de formação do aprendiz e o reconhecimento de um mestre de coco é perpassado por uma série de rituais e reconhecimento públicos em que aquele que está aprendendo é instado a provar seu valor constantemente, ao mesmo tempo em que nunca o 
deixam esquecer o lugar de aprendiz, de subalterno (Turner, 1979). Mas uma vez alçado ao lugar de mestre, conquista a posição de parceiro. $\mathrm{Na}$ narrativa do Sr. Zezinho, dois desses rituais foram contados com grande vivacidade e orgulho, pois não só ele tinha passado no teste como tivera seu valor reconhecido. O primeiro ritual foi o descrito acima, em que adquire o direito de ser aprendiz, vencendo o desafio que lhe é feito, expondo-se diante de um grande público. O segundo ritual refere-se ao reconhecimento por outro mestre de sua condição de cantador. Vejamos como o Sr. Zezinho nos relata esse processo:

Agora ele foi me ensinando as pisadas, que o mestre tem que ensinar as pisadas ao discípulo direitinho... O primeiro teste que ele fez comigo, tinha um cantador que cantava muito em Santo Amaro e se chamava Gabriel Barbeiro, ele cortava cabelo no mercado de Santo Amaro. Um dia seu João disse: "Amanhã, um dia de domingo, você chega cedo que a gente vai a Santo Amaro", não disse pra onde ia, nem pra nada... Quando eu cheguei lá disseram: “Oi João, e esse rapaz?” Aí seu João disse: "Esse rapaz anda atrás de mim praquele negócio de coco, mas ele não dá pra cantar." E eu calado. Aí disse, "Oh, Coronel (era um garoto que tinha, tinha o Tenente que era o pai, o filho que era garoto era Coronel). Vai lá no mercado e diga a Gabriel que João está aqui”". Eu não conhecia nem esse Gabriel. Daqui a pouco lá vem um cabra sarara, aquele desmantelo. Aí chegou: "Oi João. Me dá aí o pandeiro, Tenente", e levantou a perna da calça. Era o Gabriel. Mas o homem cantava muito! Não tinha voz bonita, agora João Vieira tinha uma voz sonorosa... Aí ele cantou, Gabriel cantou, e eu doido pra cantar, mas a gente só pode cantar quando o mestre manda. E eu só cantei porque Gabriel disse: "Esse rapaz?” "Mora em Casa Amarela, doido pra aprender a cantar, deixa ele cantar um pouquinho?" Aí foi quando ele disse: "É, canta um pouquinho." Aí eu cantei até um coco dele. Aí quando eu fiz o repente Gabriel parou meu pandeiro, e eu digo: "Ih! Diga mestre". Aí ele disse a seu João: "Você João, trouxe um cantador pra sacudir em cima de mim, que esse rapaz já sabe cantar! Esse rapaz é um cantador." Aí seu João: "nada rapaz, ele tá aprendendo". "Não! Esse rapaz sabe cantar! Cante outro pouco." 
Desse modo, apesar de "desqualificado" por seu mestre diante de outro cantador, a intenção de surpreender o oponente fica expressa por este quando reconhece que o Sr. Zezinho já era um cantador, revelando um sutil jogo de desafios entre mestres no qual os aprendizes também exercem um papel. Seu Zezinho tinha passado no teste, já era reconhecido pelos oponentes de seu mestre como um deles.

Essa relação mestre/aprendiz vai além, contudo, da mera transmissão de um conhecimento técnico, inserindo-se numa larga tradição oral, que percorre o Nordeste não só nos cocos e sambas de maracatu, que têm estruturas poéticas semelhantes ao cordel e à cantoria. Desse modo, não só o aprendiz precisa aprender a tocar pandeiro, a ter boa memória, mas necessita se inserir nessa rede de cantadores para aprender a tradição, as rimas ricas, os motes mais astutos, os estilos e composições mais difíceis. ${ }^{6}$

O Sr. Zezinho nunca deixou de referir-se a si mesmo como Zezinho de Zé Vieira, demonstrando mais do que respeito ou hierarquia para com o mestre que o iniciou na arte do coco e do improviso. Em muitos momentos fiquei a pensar que se tratava até mais do que respeito e transmissão de saber entre gerações, ou seja, de tradição oral. Afinal, o Sr. Zezinho começou a cantar quando era "garotote", e Zé Vieira era já mestre afamado. Foi sem dúvida, uma relação filial na qual Zé Vieira cumpria o amoroso papel de pai, além de mestre, criando situações para que Zezinho aprendesse, tivesse oportunidades, crescesse em experiências. E para isso, é preciso ser bem relacionado, conhecer não só as regras da composição, mas a cidade, os lugares onde se reúnem os cantadores, não perder oportunidades de criar fama e aprender mais, tornar-se conhecido. Tornar-se aos olhos dos outros um mestre.

Para que possa ser reconhecido como coquista de valor, é preciso entrar nessa rede de músicos e cantadores, ocupar espaços, ser conhecido, adquirir experiência. Mas havia um preço a ser pago, e seu Zezinho manifesta que um cantador não pode ter família, nem tem amor à família:

Por que o homem que canta ele não tem amor à família. O homem que é cantador não tem amor à família. Digamos que eu saio agora de tarde, vou cantar uns coquinhos na casa de um

6 Sobre tradição oral ver: Cruikshank, 2001. 
camarada. Quando chega lá, já tem outro pra me levar pra outro canto, aí termina passando a noite... Hoje eu não faço mais isso não, porque segunda-feira tem responsabilidade aqui, de despachar os Exus, de despachar a Jurema, e não posso fazer essas coisas. Eu já saí um dia de sábado de casa, e cheguei na outra segunda-feira. Eu e Antonio Roxinho, a gente brincando direto.

É preciso afirmar a condição de mestre cotidianamente, estar sempre disposto a enfrentar e vencer um desafio. Um mestre é considerado "muito bom" quando tem a maestria de circular entre a rede social e as regras da tradição oral, tecendo complexas relações entre ambas. Ser um cantador, um verdadeiro coquista, exige maestria no trato com as palavras, e na rapidez com que se é capaz de criar improvisos, responder à altura os desafios lançados nas rodas, agilidade e memória para criar quadrões, décimas, oito pés e poder "brincar" com essa variedade de regras poéticas que constituem a riqueza e complexidade do coco. E para tudo isso, afirme-se, deve-se sempre contar unicamente com o recurso da memória e agilidade mental para o improviso. Seu Zezinho foi muito explícito quando confirmou que mestre de valor é aquele que sabe improvisar, pois o cantador que no desafio lança mão de cocos que compôs anteriormente, é motivo de chacota e zombaria. Quando me cantava um samba de maracatu, e me explicava as diferenças, fez questão de afirmar:

Isto é um samba de maracatu, tem que ser tudo rimado. Se você cair numa rima dessas, o mestre tá lhe escutando, aí vai lhe chamar atenção. Diz: "Eu pensei que você sabia o que é que tava fazendo..." O outro mestre, ou o camarada sabe ou não sabe. Antigamente até o mestre de maracatu cantava de modo errado. Agora que eu vou divertir, eu to cantando, não bula comigo não, sustenta esse zabumba, e nunca rimava, mas hoje em dia é tudo na letra, rimada, pra pessoa entender. Mestre de maracatu é feito cantador de viola. Cantador de coco, cantoria de viola, o cantador de coco também faz aquele sistema. Tudo é rima, improviso, saído da idéia. E se você cantar um coco pra mim, você escrevendo pra cantar, eu conheço. Qualquer cantador de coco conhece. 
Quando lhe perguntei: "Por que não é de improviso?" O Sr. Zezinho prontamente respondeu, reafirmando sua condição de mestre:

Não é de improviso, ele tá cantando porque ele escreveu, a gente conhece. "Oia muda isso aí que tu escreveu pra cantar. Vamo cantar repente!” É porque eu canto coco assim:

Vou seguir na cantoria

Agora chegou o dia

Eu tenho uma simpatia

Quando entro em ação

Com meu pandeiro na mão

Canto só pra quem conhece

Minha fama estende e cresce

Nos oito pés de quadrão.

\section{Referências bibliográficas}

AMORIN, Maria Alice. Improvisos: uma pisa de rima. Recife: Fundação de Cultura Cidade do Recife, 2002.

ANDRADE, Mário de. O turista aprendiæ. São Paulo: Duas Cidades, 1976.

Os cocos. Pref., introd. e notas de Oneyda Alvarenga. São Paulo/Brasília: Duas Cidades/INL, 1984.

AYALA, Maria Ignez Novais. Os cocos: uma manifestação cultural em três momentos do século XX. Estudos Avançados, v. 13 n. 35, jan-abr. 1999.

CARLINI, Álvaro. Cante lá que gravam cá: Mário de Andrade e a Missão de Pesquisas Folclóricas de 1938. São Paulo, Universidade de São Paulo, 1994. Dissertação de Mestrado em História.

CASCUDO, Luís da Câmara. Dicionário do Folclore Brasileiro. Revisto, atualizado e ilustrado. São Paulo: Global, 2001.

CERTEAU, Michel de. A invenção do cotidiano. v. 1. Petrópolis: Vozes, 1998.

A invenção do cotidiano. v. 2. Petrópolis: Vozes, 2003.

COUCEIRO, Sylvia Costa. Artes de viver a cidade. Conflitos e convivências nos espaços de diversão e prazer do Recife nos anos 1920. Recife, Universidade Federal de Pernambuco, 2003. Tese de Doutorado em História. 
CRUIKSHANK, Julie. Tradição oral e história oral: revendo algumas questões. In: FERREIRA, Marieta de Morais; AMADO, Janaína. Usos e abusos da história oral. Rio de Janeiro: FGV, 2001

HARRITS, Kirsten Folke; SHARNBERG, Ditte. Encontro com o contador de histórias: um processo de aprendizado mútuo. História Oral. Associação Brasileira de História Oral, n. 3, p.25-34, jun./2000.

GINZBURG, Carlo. O queijo e os vermes. São Paulo: Companhia das Letras, 1987.

GUILLEN, Isabel Cristina Martins. Maracatus-nação entre os modernistas e a tradição: discutindo mediações culturais no Recife dos anos 1930-1940. Clio Revista de Pesquisa Histórica. v. 1, n. 21, p. 107-135, 2003.

LEVINE, Robert M. A velha usina: Pernambuco na federação brasileira. 1889-1937. Rio de Janeiro: Paz e Terra, 1980.

LIMA, Ivaldo Marciano de França. Tradição e autenticidade entre os maracatus-nação do Recife: desconstruindo uma idéia e um olhar homogeneizador. Trabalho apresentado no Encontro Estadual de História da Anpub-PB, 2004, mimeo.

LIRA, José Tavares Correia de Mocambo e cidade: regionalismo na arquitetura e ordenação do espaço habitado. São Paulo: Faculdade de Arquitetura e Urbanismo, Universidade de São Paulo, 1996. Tese de Doutorado.

NASCIMENTO, Mariana Mesquita. João, Manoel, Maciel Salustiano. Três gerações de artistas populares e sua comunicação com o massivo na perspectiva da reconversão cultural. Recife, Universidade Federal Rural de Pernambuco, 2000. Dissertação de Mestrado em Administração Rural e Comunicação Rural.

PEIXE, Cezar Guerra Maracatus do Recife. São Paulo: Irmãos Vitale, 1981.

REAL, Katarina. O folclore no carnaval do Recife. Recife: Massangana, 1990.

REZENDE, Antônio Paulo. (Des)Encantos Modernos. Histórias da cidade do Recife na década de vinte. Recife: Governo do Estado, Secretaria de Cultura/Fundarpe, 1997.

TURNER, Victor. O processo ritual. Petrópolis: Vozes, 1974.

Resumo: "Seu Zezinho", reputado pai de santo do Alto de Santa Izabel, no Recife, foi brincante quando jovem do maracatu Cambinda Estrela, como caboclo de lança. Mas também é um grande mestre de coco e, ao entrevistá-lo, fomos surpreendidos com a complexa rede cultural em que se inseria um cantador até ser considerado um mestre - rede esta que envolve uma relação de aprendizado e transmissão do saber entre gerações. Este trabalho objetiva discutir essas redes sócio-culturais nas quais se inserem os brincantes de diversas manifestações da cultura popular do Recife, e que se referem a vínculos sócio-culturais fincados não apenas na cidade, notadamente na zona norte, mas que se estendem à zona canavieira, extrapolando fronteiras estaduais. Ao mesmo tempo, é imprescindível analisar os processos de transmissão desse saber, essenciais na formação de um mestre, que exigem experiência, mas acima de tudo conhecimento e inserção nessa rede.

Palavras-chave: cultura popular; coco; maracatu. 
The Formation of a Master: Wisdoms Circulating in Popular Culture

Abstract: "Seu Zezinho", renowned Santeria priest from Alto de Santa Izabel, in Recife, was, when young, a brincante (member of folkloric group) of the Cambinda Estrela maracatu (Brazilian folkloric dance/rhythm) as a caboclo de lança (spear caboclo). But he is also a great master of coco (another Brazilian folkloric dance/ rhythm), and, when interviewing him, we were surprised by the complex cultural network in which a singer is embedded before he is considered a master - a network that involves a learning and knowledge transmission relation among generations. The goal of this paper is to discuss those sociocultural networks in which are embedded the brincantes from several manifestations of popular culture in Recife, related to sociocultural links established not only in the city, especially in the North side, but that also reach rural areas with sugarcane crops, thus crossing state lines. At the same time, it is indispensable to analyze the transmission processes of such wisdom, which are essential for the development of a master, requiring expertise and, above all, knowledge of and inclusion in those networks.

Palavras-chave: popular culture; Brazilian folklore. 